\title{
Quantitative Influence of Coke Oven Wall Irregularity on Pushing Force
}

\author{
Masato SUGIURA, ${ }^{1) *}$ Tomoyuki NAKAGAWA, ${ }^{1)}$ Takashi ARIMA, ${ }^{1)}$ Kenji KATO, ${ }^{2)}$ Michitaka SAKAIDA, ${ }^{31}$ \\ Yoshifumi MORIZANE, ${ }^{3)}$ Akihide $\mathrm{SANO}^{41}$ and Keisuke IRIE ${ }^{5)}$
}

1) Process Research Laboratories, Nippon Steel \& Sumitomo Metal Corp., 20-1 Shintomi, Futtsu, Chiba, $293-8511$ Japan. 2) Plant Engineering and Facility Management Center, Nippon Steel \& Sumitomo Metal Corp., 20-1 Shintomi, Futtsu, Chiba, 293-8511 Japan. $\quad 3$ 3) Head Office, Nippon Steel \& Sumitomo Metal Corp., 6-1 Marunouchi, 2-Chome, Chiyoda-ku, Tokyo, 100-8071 Japan. $\quad$ 4) Nagoya Works, Nippon Steel \& Sumitomo Metal Corp., 5-3 Tokaimachi, Tokai-City, Aichi, $476-8686$ Japan. 5) Oita Works, Nippon Steel \& Sumitomo Metal Corp., 1 Oaza-Nishinosu, Oita City, 870-0992 Japan.

(Received on November 19, 2012; accepted on December 22, 2012)

\begin{abstract}
Many of the coke oven batteries in Japan have been in operation for about 40 years. These coke ovens tend to become obsolete, resulting in a production impediment such as increase in pushing force. This paper proposed an experimental expression named as a resistive index that describes resistance received by a pushed coke cake being in contact with an uneven coke oven wall. The resistive index is calculated based on the shape of the deformed oven wall. Linear relationship between a resistive index and a pushing force was experimentally verified by using a simulated part of a coke oven. The resistive index was applied to actually working aged coke ovens. A newly-developed diagnosis apparatus equipped with a 3D profile measurement system was utilized to acquire irregularity data of high-temperature coke oven walls. Here, correlation between the resistive index and the force development during pushing was also clearly confirmed. From these results, it was concluded that the resistive index enables to quantitatively assess the harmfulness of damaged coke oven walls from the standpoint of a rise in pushing force. The resistive index is available for evaluating the needs and preferentiality of maintenance of damaged coke oven.
\end{abstract}

KEY WORDS: coke oven; pushing force; wall irregularity; diagnosis; resistive index.

\section{Introduction}

Most of the coke oven batteries in operation in Japan were constructed in the 1970s, the period of high economic growth. Coke ovens reaching 40 years in operation actualize a reduction in production and the deterioration of energy efficiency due to their own degraded structure. A large amount of investment will be needed to replace such oven batteries. Accordingly, it should be necessary to repair the existing coke ovens, in order to avoid the concentration of replacements.

Roughness of brick surface, facilitating the growth of carbon deposition, is typical damage of a coke oven which has been working for over a long period. It is empirically known that oven wall irregularities resulting from such damage cause a rise in the pushing force. Experimental studies on this phenomenon have been reported. ${ }^{1-5)}$ Such studies draw the conclusion that oven wall irregularities increase the pushing force. A pusher stops automatically to avoid a breakdown of an oven wall, if the pushing force exceeds a certain limit. Aged coke ovens have tended to encounter more frequent production disturbances due to pusher stoppage. However, no relationship between deformed wall and

\footnotetext{
* Corresponding author: E-mail: sugiura.76m.masato@jp.nssmc.com DOI: http://dx.doi.org/10.2355/isijinternational.53.583
}

pushing force has ever been examined in detail, as no exact observation on the overall damage situation of an oven wall has ever been possible hitherto.

The present paper thus reports on our study performed for quantifying the pushing force affected by the irregular shape of an oven wall. Firstly, in Chapter 2, an approach toward indexing an irregular state in an oven wall that is associated with a rise in the pushing force is proposed. In Chapter 3, the phenomenon in which a coke cake passes through the irregular parts of an oven wall is observed by using a laboratory setup with a simulated coke oven. The parameters in the equation indexing the irregularity were identified. Finally, in Chapter 4, measurement technology which played a vital role in the present study is overviewed. It enables to obtain the 3D profile of the overall oven wall under high temperature of $1000^{\circ} \mathrm{C}$. And, the application of indexing wall irregularities to a working coke oven is described.

\section{Indexing of Oven Wall Irregularity}

A coke cake produced in a coke oven is extruded out of the oven by being pushed out horizontally. The dominant factors regarding pushing force are the size of the coke oven, the deformation or roughening of the oven wall or oven floor, and coking condition such as coal moisture, heating temperature and coking time. In the present paper, 
the unevenness of an oven wall that becomes aggravated over the years is discussed. The unevenness of an oven wall directly affects pushing force, as a coking chamber merely has the width of approximately $450 \mathrm{~mm}$, in contrast to the length of $16 \mathrm{~m}$ or the height of $6 \mathrm{~m}$. If a protrusion exists on the oven wall, it is obvious that a moving coke cake can come into contact with the protrusion and thus receives resistance. Nevertheless, the mechanism is not simple. The coke cake is not a consolidated solid but an aggregation of coke lumps. There are interspaces, resulting from shrinkage during the time of coking, among lumps or between the lumps and the oven wall. In order for the coke to pass over any protrusion on the oven wall, it is surmised that the movement as well as the rotation of coke lumps occurs expending the interspaces, before an insufficient space for this movement causes compacted lumps to crumble. It is difficult to express such a behavior with a physical model. Therefore, the present study addresses expression in the form of an experimental equation on the relationship between the irregularities of oven wall and the resistance received by a moving coke cake.

The horizontal cross section inside the coke oven with a depression on one side of the walls is schematically shown in Fig. 1. The profile of the oven wall can be expressed by the value $\mathrm{z}$ in Fig. 1. The differential between the adjoining $\mathrm{z}$ is defined as $\Delta \mathrm{z} . \Delta \mathrm{z}$ is positive when the chamber width is narrowed in the pushing direction. Now, if the coke cake is pushed in the right direction in Fig. 1, it is assumed that resistance force is generated depending upon the steepness and length of the wall's slope in contact with the coke cake.

We defined the value named as a partial resistive index which indicates the resistance. The partial resistive index, $\mathrm{k}$, is provided based on $\Delta z$, as described in the following. The partial resistive index, $\mathrm{k}$, is considered to be zero in "Zone $(\mathrm{n}-1)$ " and "Zone $(\mathrm{n}+2)$ " in Fig. 1, as coke lumps are not in contact with the oven wall. When $\Delta \mathrm{z}$ is less than fine gap $\delta$ corresponding with the interspace between coke lumps and the oven wall, $\mathrm{k}$ is also zero. Assuming that the resistance in proportion to the power of $\Delta z_{n}$ corresponding to the gradient of the wall is created in "Zone n," where coke lumps are in contact with the wall, the partial resistive index, $\mathrm{k}_{\mathrm{n}}$, is given by Eq. (1).

$$
\mathrm{k}_{\mathrm{n}}=\left(\Delta \mathrm{z}_{\mathrm{n}}-\delta\right)^{\alpha}
$$

"Zone $(\mathrm{n}+1)$ " is a continuous slope climbing from anterior adjacent "Zone n". The value of the partial resistive index in the anterior zone multiplied by constant $\beta$ is added

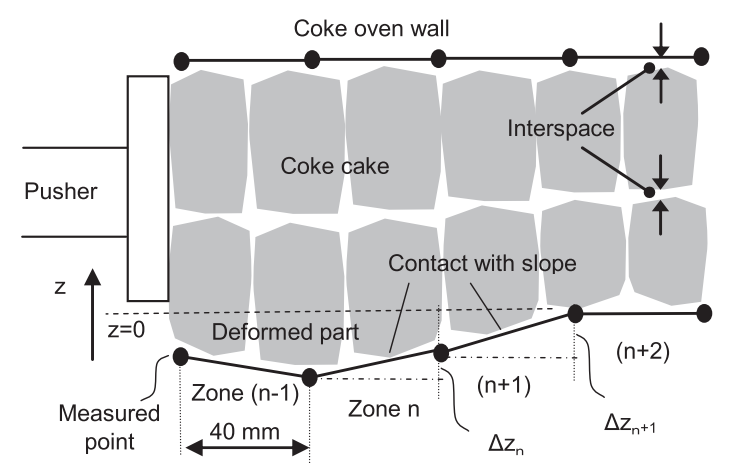

Fig. 1. Schematic depiction of a coke oven with an uneven wall. to Eq. (1) in a target zone, since it is considered that the resistance force should be higher when gaps of being $\delta$ or larger are continuous than when isolated gaps are scattered. Specifically, the partial resistive index, $\mathrm{k}_{\mathrm{n}+1}$, in "Zone $(\mathrm{n}+$ $1)$ " is presented by the following Eq. (2).

$$
\mathrm{k}_{\mathrm{n}+1}=\left(\Delta \mathrm{z}_{\mathrm{n}+1}-\delta\right)^{\alpha}+\beta \times \mathrm{k}_{\mathrm{n}}
$$

The partial resistive index is calculated from the summed value of $\Delta z$ 's in the opposing position, when the coking chamber wall has irregularity on both sides. Because the resistance against the pushed coke cake should be dictated by the displacement in the chamber width of a narrowed coke oven portion.

In turn, if the two-dimensional wall irregularity data are obtained, the partial resistive index is weighted according to the height of the oven wall. That means irregularity in the inferior part of the wall requires larger force than one in the upper part, since the lower the coke cake is situated in the coke oven, the more undeformable it is due to the constraint of self-weight. Such a condition is formularized as in the following. The partial resistive index, $k$ ', at the height of $h$ from the oven floor is expressed by the following Eq. (3) with weighing parameter $\gamma$ according to the height position;

$$
\mathrm{k}^{\prime}=\left[1+\gamma\left(\mathrm{H}_{0}-\mathrm{h}\right) / \mathrm{H}_{0}\right] \times \mathrm{k} .
$$

where $\mathrm{H}_{0}$ is the height of the whole oven.

The summed-up value over the full coverage of a oven wall with the sought partial resistive index for each zone is herein denominated as the "resistive index." Parameters $\delta$, $\alpha, \beta$ and $\gamma$ in Eqs. (1)-(3) are thus experimentally established so that the calculated resistive index from the irregularity can be linearly associated with the pushing force. The resistive index is intended for the situation in which a coke cake initially at rest is pushed to pass over an uneven area, thus gradual expansion of chamber width along the pushing direction is not considered here.

\section{Laboratory Experiment}

For completing the indexing of the oven wall irregularity as described in Chapter 2, it is necessary to perform an actual measurement of the boosted pushing force according to the diverse oven wall irregularity. As it is difficult to directly observe the behaviors of pushed-out coke cakes in an actual coke oven, a device for pushing force measurement with a partly simulated portion of the coke oven at room temperature in the laboratory was invented. ${ }^{6}$

\subsection{Pushing Test Apparatus}

The experimental apparatus is schematically shown in Fig. 2. The present apparatus is provided with two hydraulic devices, $3 a$ and $3 b$, in front of and in the rear of the coke cake, respectively, which is pushed out by the former while a certain reaction force is applied by the latter, which lies in the moving direction of the coke cake. A portion of an actual coke cake having a size of $16 \mathrm{~m}$ is thus simulated. A fixed wall is placed on each side of the coke cake, lest the distance between the side walls should vary while the coke cake is being pushed out. The pushing force, reaction force and load applied to the side walls were measured with load cells. In addition, a balance of the designated weight was loaded on 


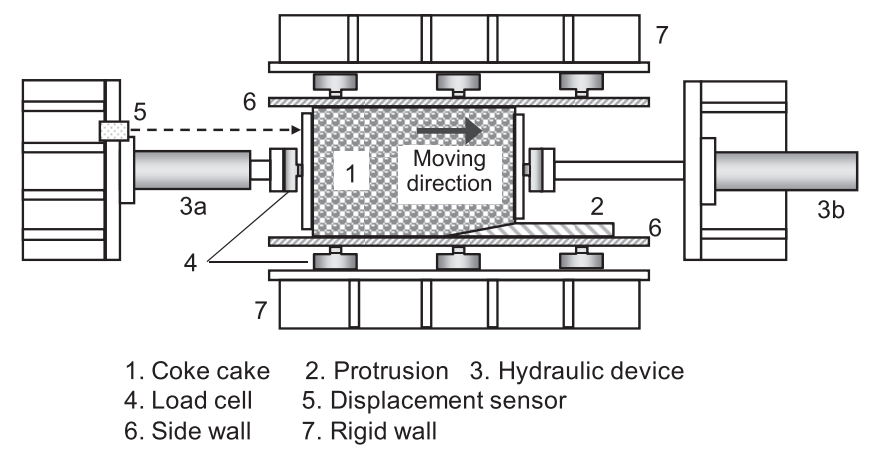

Fig. 2. Schematic of the experimental apparatus.

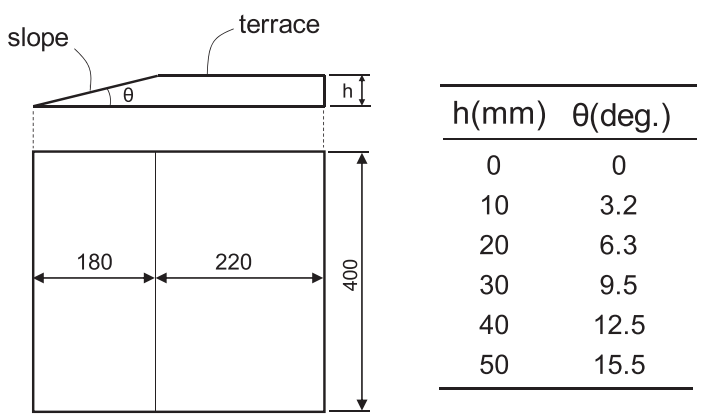

Fig. 3. Specifications of the protrusion on the side wall.

the coke cake in order to change the assumed position in the height direction in the coking chamber.

The test apparatus is arranged with a metallic plate having such a fabricated protrusion as shown in Fig. 3 on the one side of the walls, intending to simulate wall irregularity.

Metallic plates of the protrusion having height $\mathrm{h}$, i.e., a thickness ranging from $10 \mathrm{~mm}$ to $50 \mathrm{~mm}$ with an increment of $10 \mathrm{~mm}$, were prepared. The range of this shape was determined on the basis of the measurement results of actual coke ovens conducted by a later-mentioned diagnosing apparatus.

The coke cake used for testing was produced by an electric furnace in which $80 \mathrm{~kg}$ of coal (dry) filled in a box-type metallic container of W $420 \times \mathrm{H} 400 \times \mathrm{L} 610 \mathrm{~mm}$, and t 0.5 $\mathrm{mm}$, with a bulk density of $800 \mathrm{~kg} / \mathrm{m}^{3}$, was carbonized. Coking time was set at 18.5 hours with a peaking temperature of $1000^{\circ} \mathrm{C}$ at the central part in the middle of coal. The entire box-type container filled with the coke cake after terminating carbonation was accommodated in a cooling device and cooled down to room temperature in a nitrogen atmosphere. The coke strength $\mathrm{DI}^{150}{ }_{15}$ was 85.2.

\subsection{Experimental Results}

Transition of the force during pushing is shown in Fig. 4 when the protruded height was $40 \mathrm{~mm}$, the reaction force was $20 \mathrm{kN}$ (constant), and the interspace between the side wall and coke lumps was approximately $2.5 \mathrm{~mm}$. Pushing force began increasing when the pushing stroke had surpassed 100-150 $\mathrm{mm}$. The reason why there was no rise in force during the initial stage of pushing is that interspaces between the hydraulic pushing device and the coke cake were provided on the adjustment stage before measurement. As the stroke is extended further, the pushing force as well as the side wall load continued to rise and indicated an approximately constant value around $430-500 \mathrm{~mm}$. This is because the coke cake had run aground completely on the

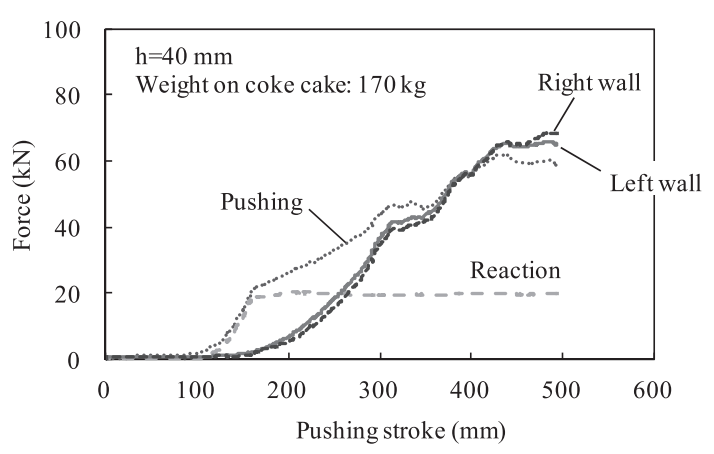

Fig. 4. Transition of the force during pushing.

Reaction force: $26.3 \mathrm{kN}$

Thickness of protrusion: $30 \mathrm{~mm}$

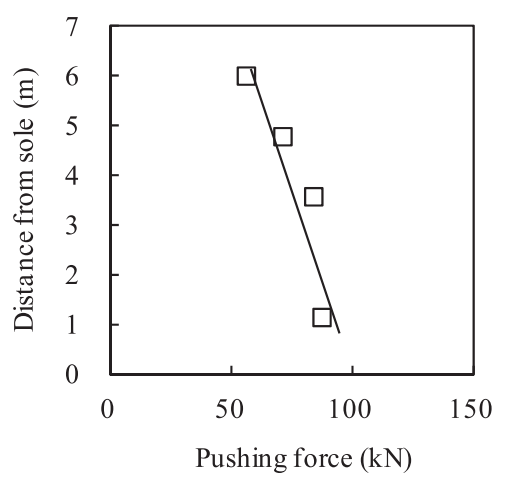

Fig. 5. Change of pushing force in the coke height direction.

terrace face of the protrusion.

In order to simulate the difference of situation between tha bottom and the top portion in coke oven, pushing-out tests were conducted varying the weight above the coke cake. Weight of $0 \mathrm{~kg}, 170 \mathrm{~kg}, 350 \mathrm{~kg}$ and $700 \mathrm{~kg}$ corresponds to the condition with the height of $6 \mathrm{~m}, 4.8 \mathrm{~m}, 3.6$ $\mathrm{m}$ and $1.1 \mathrm{~m}$ from the oven floor, respectively, when the contact area of the coke cake used for the test at the oven floor is $0.24 \mathrm{~m}^{2}$ and when the bulk density of the coke cake is $600 \mathrm{~kg} / \mathrm{m}^{3}$.

As shown in Fig. 5, the pushing force is not uniform along the oven height direction but becomes larger the closer it gets to the bottom. Here, the pushing force along the lateral axis is calculated by subtracting the friction force on the floor surface. It is demonstrated that the rise in the pushing force resulted from the protrusion can have the difference of approximately two times between the bottom part and the top part of the coke cake in a coke oven of $6 \mathrm{~m}$ in height. Weighing parameter $\gamma$ along the height direction in Eq. (3) results in $\gamma=1$.

The relationship between the protruded shape and the pushing force is shown in Fig. 6. The pushing force varies exponentially as protruded height $\mathrm{h}$ increases. This proves that any irregularity such as adhered carbon and the partial wear of bricks can widely change the pushing force according to the slope in contact with a coke cake. Parameters $\alpha$ in Eq. (2) were fitted by using the data as shown in Fig. 6. With $\alpha=1.45$, the relationship between the resistive index and the pushing force emerged to be linear as shown in Fig. 7. Here, an interspace between the side wall and the coke of $2.5 \mathrm{~mm}$ was given as amount $\delta$ in Eq. (2). 
Reaction force: $18.1 \mathrm{kN}$

Weight on the coke cake: $170 \mathrm{~kg}$

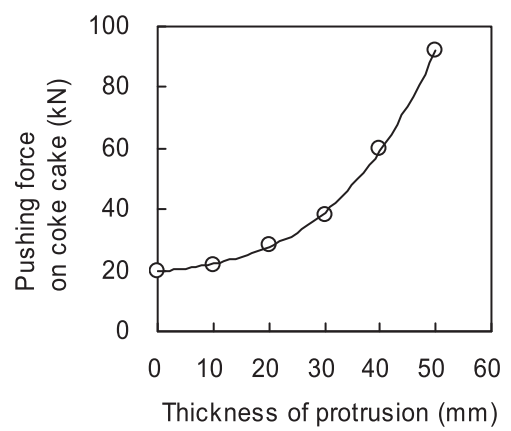

Fig. 6. Change of pushing force with the protrusion thickness.

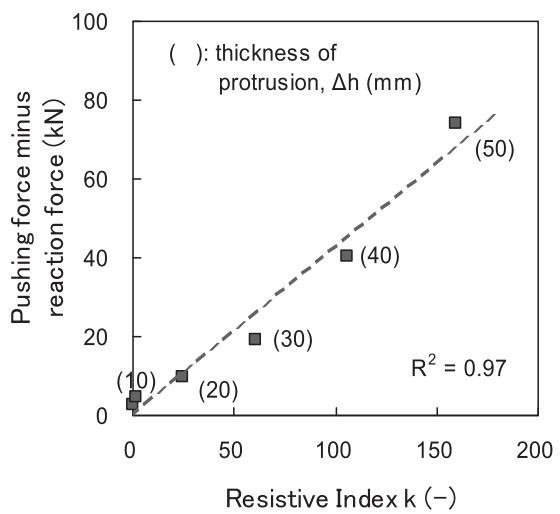

Fig. 7. Relationship between irregularity index and the force required to pass over the recessed portion.

\section{Operating Coke Oven Applications}

The inside of a coke oven made of silica bricks is constantly maintained at high temperature of $1000^{\circ} \mathrm{C}$ or beyond, so as to avoid thermal shock which may weaken brick structure. In addition, the coking chamber is only 0.45 $\mathrm{m}$ in width, in contrast to its $16 \mathrm{~m}$ in length or $6 \mathrm{~m}$ in height. Therefore, it is difficult to observe any uneven area on the oven wall inside the oven. A few types of diagnosis equipments for measuring the chamber width or imaging the wall were developed. ${ }^{7-10}$ ) However, those equipments provide only a partial view or a particular level inside the oven. Currently, we have developed a diagnosis apparatus by which the $3 \mathrm{D}$ profile of the overall wall is measurable. ${ }^{11)}$ In this chapter, first of all, the structure of this diagnosis apparatus as well as the irregularity measuring method is illustrated. Secondly, the outcome resulted from the application of resistive indexes to the wall irregularity data of operating coke oven obtained by using the diagnosis apparatus is described.

\subsection{D Profile Measurement of Oven Walls}

The diagnosis apparatus consists of a platform moving on the rails of a pusher and a heat-resistant probe. The probe travels a length of $16 \mathrm{~m}$ in a high-temperature chamber. Electronic devices for measurement such as a CCD camera, a laser and the like are mounted at the tip of the probe. Cooling water is circulated inside the probe, and cooling air is also supplied. Although the temperature inside the coking chamber is higher than $1000^{\circ} \mathrm{C}$, the temperature of the

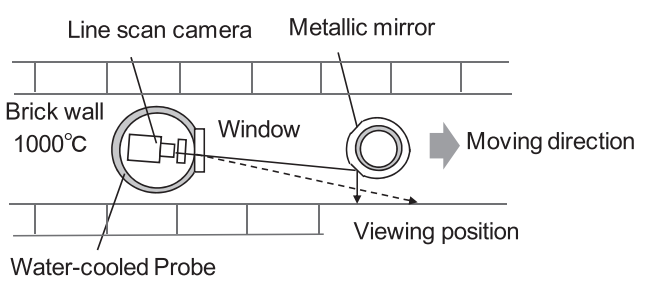

(a) Horizontal sectional view

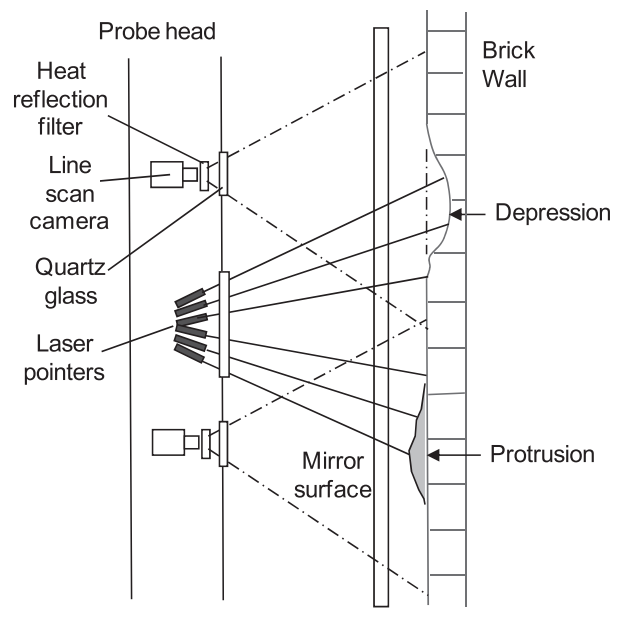

(b) Cross-sectional view

Fig. 8. The irregularity measurement system.

mounted electronic devices is retained at $40^{\circ} \mathrm{C}$ or below by virtue of these cooling functions. Special heat-reflecting glass, used for the windows of the camera and the laser, permits the transmission of only the visible light but shields the infrared ray having thermal effect.

Diagnosis using the apparatus is carried out in an empty coke oven. The probe promptly goes forward and backward in the coke oven within approximately four minutes so as to give less impact on coke production.

A horizontal section of the probe is shown in Fig. 8(a). A line scan camera, which is tipped with a linear image sensor as a photodetection element, is used. The linear viewing field of the camera is set along the vertical direction to the oven wall, and a line profile of thermal radiation is obtained for each millimeter that the probe advances. An image is created by sequentially apposing these line brightness signals on the PC's memory. The oven height of $6 \mathrm{~m}$ is covered by four cameras with 1024 pixels arranged in the vertical direction. A wall image having the resolution of $1 \mathrm{~mm}$ in the horizontal direction and $1.5 \mathrm{~mm}$ in the vertical direction is thus obtained. When the image is taken in an oven with narrow width, the camera is destined to view the wall at an acute angle as shown by the broken line in Fig. 8(a). Consequently, the unavoidable swaying of the probe moving ahead in the width direction creates the problem of a deformed image resulting from the largely unstable viewing position. As a solution for this problem, a column-shaped mirror of $6 \mathrm{~m}$ in height manufactured from a stainless steel pipe is set in front of the cameras. The mirror allows to bend the view direction so that the camera can perpendicularly observe the oven wall. Inside of the pipe is water-cooled in order to prevent high temperature oxidation of the metallic mirror surface. The camera mounted on a moter-driven 
stage rotates right and left, and it obtains each image of the right wall and the left wall on the way to and from the opposite side of the coke oven.

The irregularity measurement of the oven wall is realized by means of projecting plural laser beams from obliquely below or obliquely above in the field of view of the camera, as shown in Fig. 8(b). The laser is projected at intervals of $130 \mathrm{~mm}$, nearly equal to the height of one brick. The probe is equipped with small laser diodes of 44 pieces, which are separately positioned in the upper part and in the lower part. When the probe proceeds obtaining an image with projected laser light spots, the reflected intensities of the laser lights on the image are observed as lines in the horizontal direction. According to the principle of the light-section method, the laser line on an image is rectilinear if the wall has flatness, but the laser line fluctuates if irregularity exists. An example of the wall images is shown in Fig. 9. Irregularity formed from inconsistently grown carbon on the worn brick surface exists in the left region of this image.

The irregularity information of the oven wall obtained initially as image data is converted into profile data through

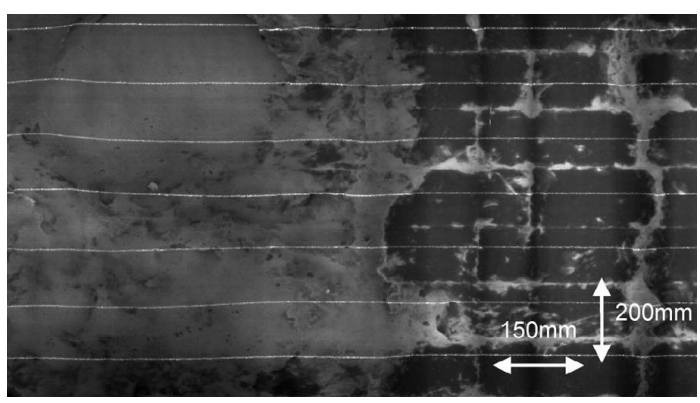

Fig. 9. An example of wall image data. image processing. The irregularity amount is calculated at intervals of $40 \mathrm{~mm}$ by the image processing, as the high intensity portion of the laser line is traced in the horizontal direction. The relationship between pixel count of the laser line displacement on the image and the actual amount of coking-chamber-wall irregularity is determined by geometrical conditions, such as laser emission angles and the image resolution of the imaging system. A 3D profile with a grid dimension of $40 \mathrm{~mm}$ in the horizontal direction and $130 \mathrm{~mm}$ in the vertical direction is obtained by the implementation of this processing, with regard to the lines of the 44 projected laser beams. An unclear laser line on an image incurs an error during line tracing processing. In order to ensure the brightness contrast of reflected laser light against the thermal radiation emitted from high-temperature wall, laser power as well as the spectral bandwidth of bandpass filters was designed. The accuracy of the irregularity measurement was confirmed as $\pm 2-3 \mathrm{~mm}$ by monitoring a simulated wall provided with an artificial bump outside the oven.

\subsection{Application Result}

Diagnosis, using the apparatus mentioned above, was carried out on a coke oven battery that has been in operation for over 30 years. A 3D profile of one portion cut out from the coke-chamber wall including relatively large depressions is exemplified in Fig. 10. The lateral axis denotes the distance from the pusher side edge, and the vertical axis denotes the height from the floor of the coke oven. The depression occurred at worn brick surface has a depth of 50 $\mathrm{mm}$ at the deepest point. The protrusion is the zone with adhered carbon. The spatial distribution of the partial resistive index calculated in respect to the shape of the wall in Fig. 10 is shown in Fig. 11.

The relationship between the resistive index and the push-

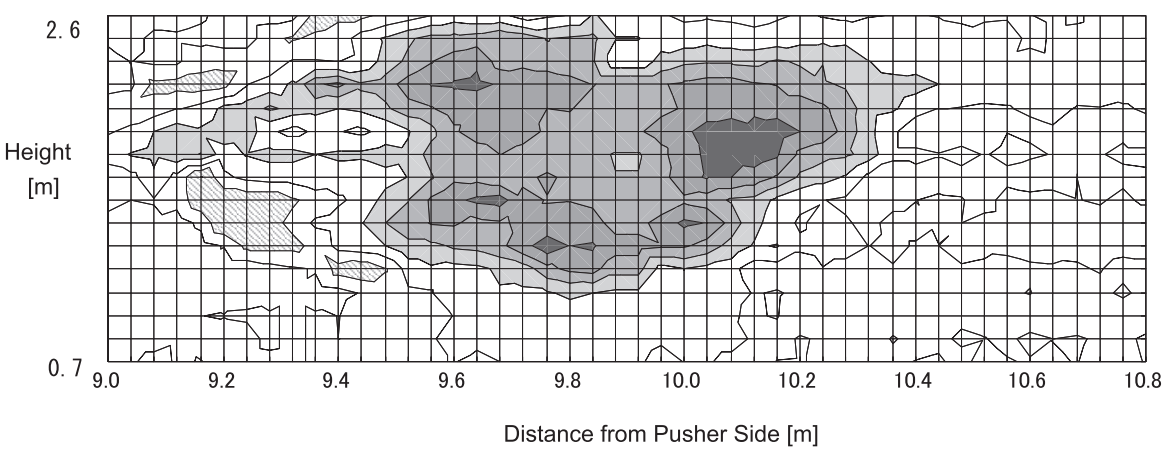

Irregularity [mm]

圆 $10.0-20.0$

$\square 0.0-10.0$

$\square-10.0-0.0$

$\square-20.0--10.0$

$\square-30.0--20.0$

$\square-40.0--30.0$

$-50.0--40.0$

Fig. 10. An example of coke oven wall terrain.

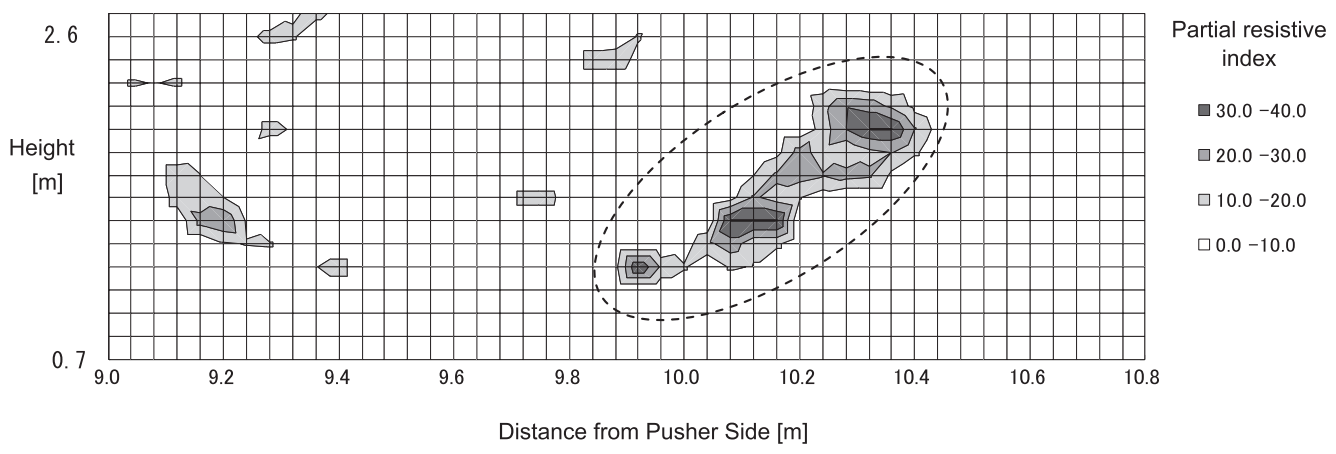

Fig. 11. Spatial distribution of partial resistive index. 


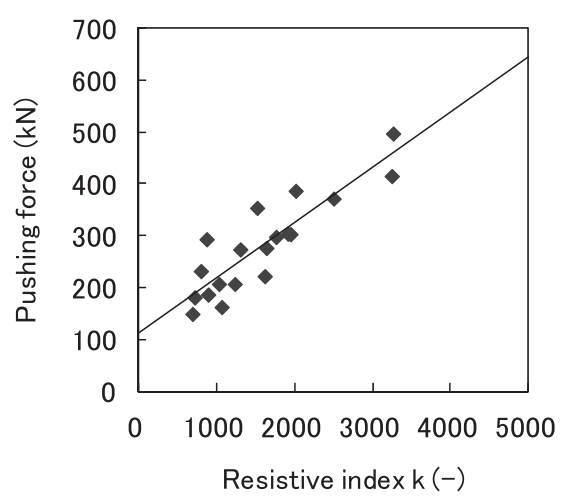

Fig. 12. Relationship between resistive index and pushing force.

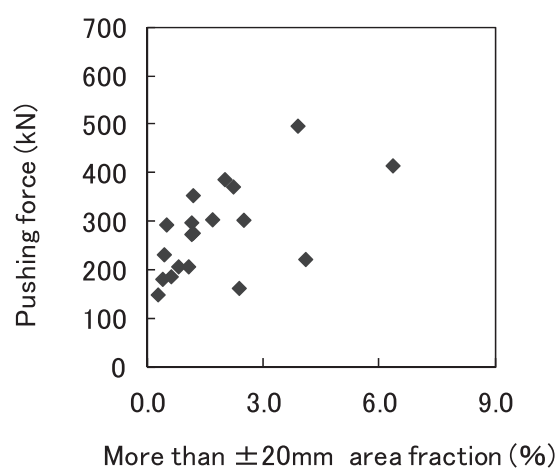

Fig. 13. Relationship between uneven area and pushing force.

ing force with regard to the 18 coke ovens are shown in Fig. 12. The pushing force is calculated from the maximum torque of the pusher's driving motor. The maximum torque is observed when an entire coke cake begins to move. The values described in Chapter 3 were used as parameters $\alpha$ and $\gamma$, in resistive indexes. Parameter $\delta$, which is corresponding to the interspace between the coke cake and the oven wall, was given as $2 \mathrm{~mm}$ by roughly considering contraction percentage during coking. The value of $\beta$ was searched in the range of 0 to 1 so as to maximize the correlation coefficient between the resistive index and the pushing force, and then it was defined as 0.2. For reasons of comparison, regarding the same coke oven, the relationship between the pushing force and the ratio of the uneven region with an irregularity of $\pm 20 \mathrm{~mm}$ or more to the overall area of the wall is indicated in Fig. 13.

\section{Discussion}

The pushing force indicates an approximate constant value in the pushing stroke range of $400 \mathrm{~mm}$ or beyond in Fig. 4. It is assumed that intense friction is produced between the compressed coke cake in the width direction and the terrace surface, even after the coke cake has passed through the slope. The force being exerted on the side wall is approximately equal to that between a wall having a protrusion and a smooth wall. The contact area between the coke cake and the terrace surface of the protrusion is $22 \mathrm{~cm}$ (terrace length) $\times 40 \mathrm{~cm}$ (height) $=880 \mathrm{~cm}^{2}$, while that between the coke cake and the smooth surface is $55 \mathrm{~cm}$ (shortened more than the initial length because of being compressed in the pushing direction) $\times 40 \mathrm{~cm}$ (height) $=2200 \mathrm{~cm}^{2}$. Therefore, the pressure being exerted on the side wall having a protusion should be 2.5 times higher than that with smooth surface. Accordingly, it is surmised that substantial pressure is produced on the side of the protrusion in the narrow width of the oven. In the experiment that resulted in the measured data as shown in Fig. 5, the action such that a coke cake hunches upward was observed, when the weight of the loaded balance on the coke cake was small. This suggests that the reason why the pushing force varies along the oven's vertical direction despite the same protruded depth is that the reaction from the protrusion is appeased, since the closer to the spacious upper portion the position is, the more likely the coke cake is to move upward.

The pushing force increases exponentially with increasing the protrusion thickness as shown in Fig. 6. The reason is that coke cake can pass over thinner protrusions with lower pushing force by the rotation of lumps and expending interspaces, while the higher pushing force as to crumble coke lumps is needed for thicker protrusions as mentioned in section 2.

Despite the correlation between the resistive index and the pushing force as shown in Fig. 12 can evidently be confirmed, the relationship between the uneven area and the pushing load as shown in Fig. 13 has poor correlation. This fact suggests that the mere size of damaged areas does not allow us to correctly assess the harmfulness of damages due to irregularity. It is worth saying that the resistive index that is focused on the shape and position of the deformed oven wall more properly reflects the mechanism of the pushing force generation.

The line found in Fig. 12 denotes an approximation linear expression of the relationship between resistive indexes and pushing forces with an ordinate intercept of $111 \mathrm{kN}$ and a gradient of 0.107 . It should be emphasized that this relational expression directly associates the wall irregularity with the pushing force. The relational expression having the intercept never falling to zero is consistent with the fact that a certain pushing force is created by the friction between the oven wall and the oven floor even if the oven wall is completely smooth. It is a future issue to be studied regarding how the relational expression varies depending upon the size of the coking chamber and the property of coal used.

In view of Figs. 10 and 11, a partial resistive index is intensively generated on the slope directed toward the pushing direction from the bottom of the large depression. Summation of the partial resistive indexes lying within the eclipse of chained line in Fig. 11 amounts to about 940. Based on the previously mentioned relational expression between the resistive index and the pushing force, it is surmised that approximately $100 \mathrm{kN}$ of resistance force arises when the coke cake passes through the depression on the wall. The resistive index can be utilized to quantify the increase of pushing force posed by an irregularity and is available for the harmfulness comparison among plural damaged oven walls.

\section{Conclusion}

This paper attempted to state that the resistant force received by a coke cake being in contact with an uneven wall area is presented by an experimental expression, for the purpose of indexing the shape of the oven wall irregularity 
linking to the pushing force. Resistive indexes that are calculated from the steepness, length, and positional height of a wall's slope which narrows oven width toward the pushing direction were proposed.

It was verified by a experiment of pushing force measurement using the simulated part of a coking chamber in the laboratory that the linear relationship between a resistive index and a pushing force can be obtained by appropriately tuning up the parameters in resistive indexes.

The resistive index was applied to the actually working aged coke oven battery. A diagnosis apparatus equipped with a $3 \mathrm{D}$ profile measurement system using the light-section method on the heat-resistant probe was developed to acquire irregularity data of the oven walls. Hereupon, it was also confirmed that there is a linear relationship between a resistive index and a pushing force.

Damages accompanied with irregularity often occur in a multitude of coke ovens of a battery under operation for a long time. The resistive index proposed in the present paper enables us to quantitatively assess the harmfulness of an uneven damage by being associated with a rise in pushing force. Hence, the resistive index is useful for managing the pushing force of each coke oven; and, in addition, it is fully available as the criteria according to which the needs and preferentiality of oven wall repairs are judged.

\section{REFERENCE}

1) K. Nishioka, H. Ueda, M. Ogawa and S. Yoshida: Coke Circular, 35 (1986), No.1, 21

2) S. Watakabe, K. Takeda, H. Suginobe and H. Itaya: Tetsu-to-Hagané, 84 (1998), No.3, 165.

3) T. Nakagawa, T. Arima, K. Kato and M. Ando: CAMP-ISIJ, 15 (2002), 766

4) S. Aizawa, K. Uebo and S. Yoshida: CAMP-ISIJ, 20 (2007), 877.

5) K. Irie, K. Abe, M. Sugiura and M. Sakaida: CAMP-ISIJ, 23 (2010), 66, CD-ROM.

6) T. Nakagawa, T. Arima, K. Fukuda, S. Nomura, M. Sugiura, M. Sakaida and K. Kato: AISTech 2010 Proc., Vol.1, AIST, Warreandale, PA, (2010), 327.

7) M. Hamaki, H. Kasaoka and Y. Tsukihara: CAMP-ISIJ, 5 (1992), No.3, 1122.

8) M. Sugiura, S. Egawa, M. Yokomizo and M. Sakaida: CAMP-ISIJ, 17 (2004), No.2, 179.

9) M. Grosse-Wilde and F. Huhn: Cokemaking Int., 8 (1996), No.2, 42.

10) M. Sugiura, M. Sakaida, S. Egawa, T. Kajiya, M. Yokomizo and S. Naito: CAMP-ISIJ, 16 (2003), No.2, 296.

11) M. Sugiura, M. Sakaida, Y. Fujikane and K. Irie: T. SICE, 47 (2011), No.10, 435 . 